\title{
CULTURA E POLÍTICAS PARA AS ARTES
}

Gisele Marchiori Nussbaumer

gicamn@gmail.com

Neste texto destacamos mudanças históricas ocorridas na compreensão da palavra cultura, sua importância e influência no que se refere às políticas para as artes e a cultura no Brasil. Partimos da premissa que as políticas para as artes confundem-se com as políticas culturais e que, para que haja avanços nas políticas específicas, é necessário, por um lado, refletir sobre o que se entende por artes e as transformações pelas quais as linguagens artísticas vêm passando e, por outro, que elas se aproximem da esfera do cotidiano, tornando-se cada vez mais públicas.

\section{A ideia de cultura}

Em seu livro A ideia de cultura, Terry Eagleton (2005) destaca a complexidade da palavra cultura, ao mesmo tempo ampla e restrita demais, e ressalta que se o seu significado antropológico abrange praticamente 
tudo, "[...] o sentido estético da palavra inclui Igor Stravinsky, mas não a ficção científica”. A tese do autor é que “[...] estamos presos, no momento, entre uma noção de cultura debilitantemente ampla e outra desconfortavelmente rígida”. (EAGLETON, 2005, p. 51) Eagleton lembra que, etimologicamente falando, o conceito de cultura é derivado do de natureza, significando tanto o que está a nossa volta como o que está dentro de nós. Nesse sentido, a ideia de "cultivo" aparece como um dos seus sentidos originais, mas cultivo não apenas de nós mesmos, também aquele que pode ser feito a nós, em especial pelo Estado, uma vez que a cultura é

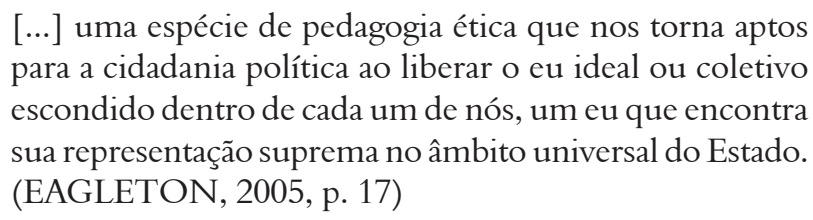

A cultura seria uma forma de sujeito universal e o Estado, a presença do universal no âmbito da sociedade.

Baseado em Raymond Willians (1992) e em sua análise da história da palavra cultura, Eagleton (2005, p. 19-30) discorre sobre as suas diferentes significações tendo como referência os três sentidos modernos principais a ela atribuídos, ou seja, cultura como "civilidade ou civilização", "modo de vida característico" e "especialização às artes" (sinônimo das grandes artes, restritas a uma pequena elite). O primeiro significado de cultura, como “civilidade ou civilização", em grande medida uma noção francesa, remonta aos costumes e a moral do século XVIII e passa ser um problema no final do século XIX, quando os aspectos descritivos e normativos da palavra "civilização" começam a se separar (adjetivo "civilizado"). A partir do idealismo alemão emerge, em contraposição a esse significado, a ideia de cultura como "modo de vida característico", estreitamente ligado a um pendor român- 
tico anticolonialista e, mais tarde, a uma romantização da cultura popular. Instala-se o conflito entre "cultura e civilização", sendo a cultura ao mesmo tempo aristocrática e populista e a civilização essencialmente burguesa. Cultura passa a ser entendida como quase o oposto de civilidade e investe-se em uma pluralização do conceito, que só se estabelece no início do século XX. Como resume Eagleton (2005, p. 29),

[...] se a primeira variante importante da palavra cultura é a crítica anticapitalista, e a segunda um estreitamento e, concomitantemente, uma pluralização da noção a um modo de vida total, a terceira é a sua gradual especialização às artes.

O terceiro significado moderno da palavra, cultura como especialização às artes, abrange desde a atividade intelectual (Ciências, Filosofia) até as artes canônicas (Artes Plásticas, Literatura etc.). O problema em relação a essa variante é que "[...] tão logo cultura venha a significar erudição e as artes atividades restritas a uma pequena proporção de homens e mulheres, a ideia é ao mesmo tempo intensificada e empobrecida”. (EAGLETON, 2005, p. 29) Essa sacralização das artes (ou da cultura enquanto artes), de perspectiva romântico-modernista, logo se torna incômoda, inclusive para os próprios artistas. É somente com o pós-modernismo que as artes se livram, em parte, da pressão que passa a existir.

Os três sentidos da palavra cultura, sistematizados por Willians e retomados por vários outros autores, como Eagleton, não são facilmente separáveis e persistem até os dias atuais. Como veremos adiante e como destaca Eneida Leal Cunha (2009, p. 3), no texto A emergência da cultura, a questão hoje não é mais providenciar um conceito de cultura que dê conta de todas as suas dimensões, pois não somos capazes de enunciá-lo, 
[...] nosso problema principal não é dizer que o que a cultura é ou o que é cultura, mas buscar identificar e compreender as significações, os sentidos e os valores que historicamente foram atribuídos a palavra cultura - as suas diferentes emergências em circunstâncias históricas específicas - e após isso, avaliar quais dessas significações ainda vigoram em nossos dias, para quem vigoram e como se dá o embate entre as diferentes apropriações da palavra (e da própria cultura).

Para Cunha (2009, p. 8), é preciso identificar as forças que passam a disputar significação cultural e, nesta perspectiva, a autora privilegia duas vertentes: uma relacionada à nacionalidade e a outra às artes. A primeira vertente remonta a constituição dos estados modernos, quando a cultura passa a equivaler à identidade nacional, sendo que "o que está na pauta dos debates e das disputas contemporâneas é justamente a ideia de uma identidade estável e homogênea, sob os auspícios do Estado Nacional". As demandas hoje, no que tange a questão identitária, emergem principalmente enquanto expressão de experiências minoritárias, dos afrodescendentes, mulheres, LGBT, comunidades indígenas, entre outros. Já a segunda vertente de significação em disputa, a que mais nos interessa aqui, refere-se à contestação contemporânea da equivalência entre "cultura e artes canônicas" e a paralela separação entre "cultura e mundanidade". Nessa perspectiva, a propalada diluição das fronteiras entre a "alta cultura" (da minoria) e a "baixa cultura" (da maioria) é relativa, pois, como demonstra a autora, do ponto de vista do valor cultural, a hierarquia prevalece e se manifesta em diversos planos.

Sabemos que o filme e mais ainda a novela de televisão não equivalem ao romance; que a fotografia não tem o mesmo prestigio ou valor social (nem o mesmo valor mercadológico) que a pintura; que um recital de Beethoven 
é ainda considerado muito mais "cultural" do que uma roda de samba ou um show de rock. Mas existem hierarquizações mais sutis (e mais perversas) que atuam sobre nós com grande eficácia: não cogitamos, por exemplo, que um leitor de O Cortiço, de Aloísio de Azevedo, corra o risco de se tornar racista, mas nos preocupamos séria e honestamente com o poder alienante que a televisão pode ter sobre o seu público. (CUNHA, 2009, p. 9)

A emergência da crítica cultural - e acrescentamos da política cultural - enquanto campo de estudo, “[...] dá-se justamente no contexto da convivência e do embate entre essas diversas e diferenciadas dimensões ou significações da cultura." (CUNHA, 2009, p. 9)

\section{As dimensões da cultura e a constituição do campo cultural}

Albino Rubim (2006), no texto Políticas culturais entre o possível e o impossível, ao falar das conformações da cultura contemporânea e reivindicar a sua transversalidade ou mesmo centralidade, registra que na modernidade temos a autonomização do campo cultural em relação a outros domínios, como a religião e a política, e que tal autonomização implica na constituição da cultura como em campo singular. No entanto, tanto quando nos referimos à autonomização do campo cultural, ou quando pensamos nos eixos que o perpassam da modernidade à contemporaneidade, predomina quase sempre uma determinada dimensão da cultura, a socialmente organizada, que desde a emergência do significado moderno de cultura como equivalente às artes, até o momento atual (apesar das mudanças recentes), acaba sendo sempre privilegiada nas políticas culturais. 
Como explica Isaura Botelho (2001, p. 3), em seu texto As dimensões da cultura e o lugar das políticas públicas, embora as dimensões antropológica e sociológica da cultura sejam igualmente importantes, a distinção entre as duas é fundamental, pois tem determinado o tipo de investimento governamental feito em diversos países, "alguns trabalhando com um conceito abrangente de cultura e outros delimitando o universo específico das artes como objeto de sua atuação". Na dimensão antropológica, a cultura se produz através da interação dos indivíduos, no cotidiano, a sociabilidade é um dado básico. A dimensão sociológica, diferente da antropológica, não se constitui no plano do cotidiano do indivíduo, mas sim em âmbito especializado:

[...] refere-se a um conjunto diversificado de demandas profissionais, institucionais, políticas e econômicas, tendo, portanto, visibilidade em si própria. Ela compõe um universo que gere (ou interfere em) um circuito organizacional, cuja complexidade faz dela, geralmente, o foco de atenção das políticas culturais, deixando o plano antropológico relegado simplesmente ao discurso. (BOTELHO, 2001, p. 5)

A dimensão sociológica refere-se aquelas construções que fazem parte dos sistemas socialmente organizados, do circuito organizado da produção, circulação e consumo daquilo que o senso comum entende por cultura, as linguagens artísticas em sentido estrito.

No livro O mercado da cultura em tempos (pós)modernos (2000), em que analiso a mercantilização da cultura na perspectiva dos diversos atores sociais envolvidos, fica evidente a predominância da compreensão de cultura como equivalente às artes desde a época do mecenato até a do marketing cultural, assim como os fortes vínculos existentes entre cultura e identidade nacional e cultura 
e artes canônicas, que muito influenciaram nas políticas culturais no Brasil e contribuíram para que a dimensão antropológica ficasse relegada a segundo plano.

Cândido de Almeida (1992) identifica três momentos históricos marcantes nos quais as artes tiveram grande destaque e importância, tanto na perspectiva de constituição de um campo (ou mercado) da cultura como, também, no que se refere às relações entre cultura e Estado. O primeiro momento é àquele que deu origem ao termo mecenato. Mecenas foi o articulador da relação estabelecida entre o poder constituído pelo Império Romano e os artistas da época, a partir da premissa de que é dever do Estado promover as artes. O segundo é o início da Renascença, com o ressurgimento das artes, quando os mecenas começam a se fazer notar nos países europeus pelo acúmulo de capital advindo de uma burguesia emergente. $\mathrm{O}$ terceiro momento teve como cenário os Estados Unidos do século XIX e início do século XX, quando o país entra numa fase de desenvolvimento econômico e começam a aparecer as primeiras fortunas, como as dos Rockfeller e dos Ford. Dá-se nesse contexto o fortalecimento das artes e, a partir das décadas de 1920 e 1930, o eixo das atenções passa a ser Nova York, ao invés de Paris.

Almeida destaca que, no curso da história, é possível observar claramente a ação ideológica do Estado através do trabalho de artistas e intelectuais. Na pintura soviética de 1920 a 1940, por exemplo, encontra-se a representação dos super-homens, responsáveis por super-colheitas, essa grandeza expressa na arte da época representava o modelo de trabalhador desejado pelo Estado. Na Alemanha dos anos 1930, a propaganda apontava a necessidade de distinguir a arte alemã de uma arte menor, judia e negra.

No Brasil, várias personalidades tiveram seus nomes associados à figura de um mecenas protetor, seja apoiando artistas princi- 
piantes, seja à frente de grandes projetos culturais. Ao analisar retratos da elite brasileira nas décadas de 1920 a 1940, Sérgio Miceli (1996) destaca a figura de Olegário Mariano como mecenas de um dos mais importantes pintores nacionais, Cândido Portinari, e a importância de sua atuação para o tornar conhecido. Vários outros artistas, por se vincularem de alguma forma ao mecenato político, acabaram por ter suas imagens associadas aos dirigentes da época. Figuras como Carlos Drummond de Andrade, Villa-Lobos, Oscar Niemeyer e Cecília Meireles passaram a servir o Governo Getúlio Vargas contribuindo para legitimar a busca do nacionalismo que caracterizou o período.

Como ressaltado por Cunha (2009) e exemplificado na análise de Miceli (1996), a nacionalidade e as artes (as belas artes) destacam-se como vertentes privilegiadas na disputa por significação cultural em muitos momentos da nossa história e, por essa razão, devem ser consideradas nos estudos sobre o campo e as políticas culturais no Brasil, em particular nas quase inexistentes análises sobre políticas para as artes.

\section{Políticas culturais no Brasil}

Ao refletir sobre a história das políticas culturais do "Estado nacional brasileiro", no texto Políticas culturais no Brasil: tristes tradições, enormes desafios, Albino Rubim (2007) destaca que, apesar de Marcio de Souza (2000) ter proposto a inauguração das políticas culturais do Brasil no Segundo Império, devido à postura de mecenas de Dom Pedro II, para ele dois outros experimentos é que de fato inauguram as políticas culturais em nosso país:

a passagem de Mario de Andrade pelo Departamento de Cultura da Prefeitura da cidade de São Paulo (1935-1938) 
e a implantação do Ministério da Educação e Saúde, em 1930, mais especificamente a presença de Gustavo Capanema, à frente deste ministério de 1934 até 1945”. (RUBIM, 2007, p. 15)

Apesar das contribuições e avanços relativos esse período, inclusive com a criação de diversas instituições, muitas delas no período da ditadura, no que se refere à atuação de Mario de Andrade critica-se a predominância de "[...] uma certa visão iluminista de imposição da cultura de elite” (RUBIM, 2007, p. 16), já no que se refere a gestão de Gustavo Capanema critica-se a forte relação que se estabelece entre autoritarismo e políticas culturais.

Conforme Rubim, o intervalo democrático de 1945 a 1964 caracteriza-se por um desenvolvimento da cultura brasileira sem correspondência nas políticas culturais, que praticamente inexistem; de 1964 até 1968, apesar da repressão, temos um movimento cultural circunscrito às classes médias; do final de 1968 até 1974 ocorre um "[...] vazio cultural, apenas contrariado por alguns projetos culturais e estéticas marginais.” (RUBIM, 2007, p. 21) Daí até o início de 1985, vigora a tradição da relação entre autoritarismo e políticas culturais e o regime "[...] para realizar a transição sob sua hegemonia busca cooptar os profissionais da cultura." (ORTIZ, 1986, apud RUBIM, 2007, p. 21) São ampliados os investimentos na área e criadas inúmeras instituições, como a Fundação Nacional das Artes (1975), da qual falaremos adiante. Com o fim da ditadura, tem-se o contexto esperado para a criação do Ministério da Cultura (MinC), em 1985. Durante o governo José Sarney (1985-1989) é criada a primeira lei de incentivo fiscal, a Lei Sarney, de 1986, substituída em 1991 pela Lei Rouanet, no governo Collor de Melo (1992-1994). Em 1990, durante sua desastrosa gestão, Collor extingue as principais instituições culturais do país e cria o Instituto Brasileiro de Arte e Cultura 
(IBAC), ligado à Secretaria de Cultura da Presidência, englobando a Funarte, a Fundação Nacional de Artes Cênicas e a Fundação do Cinema Brasileiro. Quatro anos depois, em 1994, a Funarte viria a substituir o IBAC.

De 1985, quando foi criado o Ministério da Cultura no Brasil, até 2003, quase vinte anos depois, quando o cantor e compositor Gilberto Gil assume a pasta no Governo de Luiz Inácio Lula da Silva, o MinC pouco avançou em termos de atuação, visibilidade e representatividade.

\section{O Ministério da Cultura de Gilberto Gil e Juca Ferreira}

A nomeação de Gil como Ministro da Cultura criou muita expectativa, sobretudo no meio cultural, uma vez que, diferente de seu antecessor, o cientista político Francisco Weffort, tratava-se de um artista reconhecido internacionalmente à frente do MinC. A gestão de Weffort (1995-2002) sob a presidência de Fernando Henrique Cardoso caracterizou-se, como sabemos, por privilegiar um modelo que transferia para a iniciativa privada o poder de decisão sobre que projetos deveriam ser financiados ou não pelo Estado, a Lei Rouanet se tornou um instrumento para o marketing das empresas, que logo adotaram o slogan a "cultura é um bom negócio". Cultura entendida como artes e submetida, agora, ao mercado.

A gestão de Gil (2003-2008), continuada por Juca Ferreira (20082010), muda completamente o panorama das políticas culturais no País ao programar e promover uma política pública de cultura baseada no diálogo com a sociedade e em um conceito mais amplo de cultura, para além das artes e das grandes produções culturais, 
nas quais estavam focadas as atenções do Estado. Logo no início de sua gestão, Gil declarou que o Ministério passaria a tratar da cultura a partir de um conceito abrangente, considerando-a em suas três dimensões: como fato simbólico, direito de cidadania e economia. Deixou claro também que os privilegiados não seriam apenas os artistas consagrados, mas a diversidade da produção cultural brasileira.

O Ministério não pode, portanto, ser apenas uma caixa de repasse de verbas para uma clientela preferencial. Tenho, então, de fazer a ressalva: não cabe ao Estado fazer cultura, a não ser num sentido muito específico e inevitável. No sentido de que formular políticas públicas para a cultura é, também, produzir cultura. No sentido de que toda política cultural faz parte da cultura política de uma sociedade e de um povo, num determinado momento de sua existência. No sentido de que toda política cultural não pode deixar nunca de expressar aspectos essenciais da cultura desse mesmo povo. Mas, também, no sentido de que é preciso intervir. Não segundo a cartilha do velho modelo estatizante, mas para clarear caminhos, abrir clareiras, estimular, abrigar. Para fazer uma espécie de 'do-in' antropológico, massageando pontos vitais, mas momentaneamente desprezados ou adormecidos, do corpo cultural do país. (GIL, 2003)

Um avanço importante da gestão Gilberto Gil - Juca Ferreira foi o estabelecimento de uma política de fomento para a área e a institucionalização dos editais como instrumento de seleção e apoio a projetos culturais. A adoção desse mecanismo contribuiu para a descentralização dos recursos e transparência na seleção de projetos. Foi significativo o aumento do número de editais lançados e de projetos contemplados durante esses oito anos, inclusive devido ao uso crescente de editais também por empresas estatais como a Petrobrás, o Banco Nacional do Desenvolvimento Social (BNDES) e o Banco do Nordeste (BNB). 
Hoje muitas empresas, não apenas estatais, têm uma política cultural clara e vem adotando os editais como forma de seleção de projetos artístico-culturais. Uma das razões para isso é que o MinC soube divulgar sua política não apenas na agenda do Gover-no, mas também na de boa parte da sociedade brasileira que, cada vez mais, reconhece a importância da cultura e a compreende como um direito de todo o cidadão. Nesse contexto, e até mesmo por falta de outro mecanismo que o substitua, o edital passou a ser identificado como um instrumento democrático e o seu uso a ser valorizado a ponto de poder agregar valor à marca de empresas patrocinadoras, o que não poderia se imaginar na década de 1990, quando a lógica do marketing reinava soberana, com o poder de decisão nas mãos das empresas, sem uma participação e regulação mais eficiente do Estado.

A valorização e o investimento na diversidade cultural também foi uma marca importante da gestão Gilberto Gil - Juca Ferreira no MinC, tendo sido criadas políticas específicas para segmentos que, até então, não eram contemplados pelas suas políticas culturais. É o caso dos afrodescendentes, LGBT, ciganos, juventude, pessoas com deficiências, grupos e manifestações da "cultura popular".

A potencialização da produção artística e cultural foi realizada através de iniciativas como os Pontos de Cultura, Pontos de Leitura e Cineclubes, entre outras que possibilitaram que criadores e produtores passassem a atuar em rede e que o público tivesse mais acesso a essa produção. No final de 2010, conforme a publicação Oito anos de cultura, tínhamos no país cerca de 2,5 mil Pontos de Cultura, 1.681 Cines Mais Cultura, 1.275 Pontos de Leitura e 122 Pontos de Cultura Indígena. (BRASIL, 2010, p. 28)

Os esforços do MinC para adequar-se, em termos de diretrizes, estrutura, instrumentos e orçamento, à nova política e a realidade da produção cultural brasileira resultaram, no final da gestão de 
Juca Ferreira, em 2010, no Programa Nacional de Fomento e Incentivo à Cultura/ProCultura. O Programa, discutido amplamente, altera a Lei Rouanet, principal mecanismo de renúncia fiscal do Ministério, visando a reverter, dentre outras distorções, a má distribuição dos seus recursos. A renúncia fiscal é mantida, mas são revistas as faixas de incentivo. O Fundo Nacional de Cultura (FNC), constituído de recursos destinados à execução de programas, projetos ou ações culturais, passa a ser, como reivindicado por diversos segmentos da sociedade, o principal mecanismo de financiamento na área, com $40 \%$ das dotações orçamentárias do MinC.

Apesar dos resultados obtidos, da maior visibilidade do MinC, do protagonismo que as políticas culturais assumiram nos últimos anos e da criação de importantes programas, o orçamento anual do Ministério mal chegou a $1 \%$ do total das receitas do Governo Federal. Como comenta Eduardo Saron (2010, p. 189), Diretor Superintendente do Itaú Cultural, em entrevista publicada no livro Produção Cultural no Brasil,

[...] em 2008 o mecenato era quatro vezes maior que o Fundo Nacional de Cultura, e o orçamento do Ministério da Cultura era o penúltimo orçamento da União. Só ganhava do Ministério da Pesca, que tinha acabado de ser criado. Esse desequilíbrio é o grande problema, em relação ao patrocínio, ao incentivo público brasileiro, ou à operação de injeção de recursos no mundo da cultura. Foi esse desequilíbrio que fez com que o mecenato virasse a ovelha negra, mas, na verdade, o mecenato não é ovelha negra. A ovelha negra é a distância desses outros dois espaços de recursos. É preciso mexer na Lei Rouanet, porque, afinal, ela tem 18 anos. Sempre falo que a Lei Rouanet surge antes da internet, e só por isso já merece ser revista. 
A expectativa, passada a gestão Gilberto Gil - Juca Ferreira, é que o ProCultura possa vir a assegurar uma distribuição mais equânime de recursos em todo o território nacional e corrigir distorções causadas por um sistema baseado no incentivo fiscal - que acabou por provocar uma concentração de $70 \%$ dos recursos do MinC no eixo Rio - São Paulo. Há uma expectativa também em torno do Vale Cultura e da Proposta de Emenda à Constituição 150/03, ou PEC 150, que define um patamar mínimo de investimento público em cultura com, respectivamente, $2 \%, 1,5 \%$ e $1 \%$ do orçamento da União, dos estados e dos municípios.

O MinC tem hoje visibilidade internacional e uma imagem contemporânea, construída a partir de uma compreensão expandida, articulada e complexa de cultura. Espera-se que no governo de Dilma Rousseff, iniciado em 2011, haja continuidade em relação ao trabalho realizado e avanço em relação a questões importantes, como a votação do Vale Cultura e as mudanças tão aguardadas na Lei Rouanet. O que vem ocorrendo, no entanto, é que as primeiras ações da ministra Ana de Hollanda indicam um certo rompimento com o processo de continuidade. Além de ter perdido protagonismo político nesse primeiro ano, o MinC também sofreu cortes em seu orçamento. Isso sem falar das polêmicas associadas à gestão de Ana de Hollanda, como a retirada do selo Creative Commons do site do MinC.

\section{A Funarte e as políticas para as artes}

No que se refere às políticas específicas para as artes, a Fundação Nacional de Artes (Funarte), instituição criada em 1975, dez anos antes do Ministério da Cultura, é o órgão responsável, no âmbito Federal, pelas políticas públicas para as linguagens artísticas - artes visuais, dança, música, teatro e circo. 
Como registra Isaura Botelho (2000, p. 27), no livro Romance de Formação: Funarte e a política cultural, ao refazer o itinerário institucional da Funarte,

[...] a criação do Ministério da Cultura - MinC, em 1985, traz sérias conseqüências para todas as instituições do sistema. Perda de autonomia, superposição de poderes, falta de uma política cultural definida, corrida por cargos, funcionários despreparados vindos de outras áreas, clientelismo dos Estados. As alterações no diálogo com a sociedade começam a se fazer sentir pelo deslocamento dos caminhos tradicionais de financiamento: o MinC arrebata parcela considerável dos interlocutores das instituições, e a primeira lei de incentivos fiscais é promulgada em 1986. Desta forma a vertente agência de financiamento da Funarte vai se tornando secundária, e ela se vê, no final da década, reduzida fundamentalmente a uma instituição realizadora de projetos próprios.

A instituição que chegou a ser considerada "organização-modelo", conhecida como a "que apoiava", a partir da criação do MinC perde força política, tem seus dirigentes e corpo técnico desempoderados, sua força política reduzida e quase chega a ser desmantelada. Passadas décadas, a Funarte nunca mais voltou a ter o prestígio que teve nos seus primeiros anos, nem mesmo na gestão de Gilberto Gil.

Há quase um consenso no meio cultural de que nos últimos oito anos, a exemplo do que ocorreu nas gestões anteriores, o MinC pouco avançou em relação ao que poderia e deveria no que se refere a uma política para as artes no país. Como registrou o próprio Gil (2004), em um texto intitulado O papel fundamental da Funarte no Ministério da Cultura,

[...] poucas instituições públicas foram tão vilipendiadas nos anos de hegemonia do neoliberalismo como a Funarte. Chegou a ser formalmente extinta e quase liquidada; 
salvou-a o impeachment do presidente que pretendia afastar completamente o Estado da cultura. Desde então, muito pouco foi feito para a Funarte recuperar a força que, paradoxalmente, teve durante a ditadura militar, quando era um dínamo da bandeira que empunhamos agora: a ampliação do acesso do povo brasileiro aos meios de produção e ao consumo e fruição de bens culturais. A Funarte teve uma potência que deve ser resgatada.

Também seu sucessor, Juca Ferreira (2008), no discurso de posse como ministro, destacou a necessidade de uma maior atenção por parte do MinC para com as artes:

O ministério precisa redefinir seus desafios, suas metas e uma delas é fortalecer a Funarte e em diálogo com os artistas, construir as políticas de dança, de teatro, de artes visuais, de fotografia e de todas as linguagens que estão sob a responsabilidade da Funarte, que foi a instituição mais desestruturada por aquele golpe que tivemos das instituições culturais no governo Collor. Acho que faltou um pouco de perspicácia nossa, a gente deveria ter investido um pouquinho mais na Funarte e nas políticas para as artes.

No início do Governo Lula, em 2003, a Funarte passou por uma reestruturação e duas diretrizes principais passaram a pautar suas ações: o uso crescente de editais e a descentralização dos recursos. O fato de não possuir representações em todas as regiões brasileiras, no entanto, torna mais difícil a tarefa de descentralizar. A Funarte tem instalações em Brasília, São Paulo, Belo Horizonte e Rio de Janeiro, onde fica sua sede.

Outra mudança fundamental da Funarte refere-se ao foco de suas ações que, conforme a publicação Oito anos de cultura, passou, em alinhamento com o MinC, "[...] a ser toda a sociedade brasileira e não apenas os artistas. O próprio conceito de arte foi expandido, contemplando as novas linguagens, a revolução tecnológica e as intervenções interativas contemporâneas.” (BRASIL, 2010, p. 93). 
O fato de o Ministério trabalhar com um conceito amplo da cultura, destaca Isaura Botelho (2007), tem a vantagem de possibilitar que as instituições a ele vinculadas possam conduzir e se dedicar mais as políticas específicas de suas áreas. Conforme a autora, um dos principais instrumentos utilizados para isso são as Câmaras Setoriais correspondentes às diversas expressões artísticas, que articulam uma mobilização de cada setor. Estas câmaras buscam promover um amplo processo de discussão sobre políticas e planos, estabelecer prioridades e possibilitar "[...] um processo de diálogo contínuo para a construção e avaliação de políticas públicas a serem conduzidas pela instituição responsável pelas artes no âmbito do ministério, que é a Fundação Nacional de Artes". (BOTELHO, 2007, p. 130)

O conceito amplo da cultura - ou a expansão do sentido antropológico da cultura e a revisão do sentido das artes -, que vem sendo adotado não apenas no Brasil, na avaliação de Ana Maria Ochoa Gautier (2002, p. 17), traz consigo mudanças profundas na valorização do artístico que precisam ser consideradas:

O estético, como valor em si mesmo, passa para o segundo plano, ao tempo em que se pede a cultura e as artes que cubram os vazios deixados pela política. Dessa perspectiva a arte se instrumentaliza: parece que somente terá significado quando servir para restaurar comunidade, restaurar o tecido social, transformar as histórias de exclusão em histórias de reconhecimento cultural. ${ }^{1}$

Para a autora, as fronteiras entre arte, cultura e política tem se transformado radicalmente nas últimas décadas e o que queremos dizer com cultura e a maneira como se justifica o sentido da arte na sociedade estão em disputa. A cultura é cada vez mais requisitada como área crucial de intervenção na ordem social e política, incluindo aí, em particular, as artes, que permanecem como foco central das políticas, apesar do paradigma da diversidade. 
De fato, o que deveria estar no centro dos debates, no que se refere a políticas específicas para as artes, é o papel e a expansão também do que se entende por artes, para além das belas artes ou das artes canônicas, e as transformações pelas quais as linguagens artísticas vêm passando, sobretudo, considerando a valorização das tecnologias de comunicação e sua imbricação crescente no campo da cultura - fato que não é recente, mas cuja dimensão assume uma força maior à medida que a cultura digital passa a ser reconhecida nos discursos e programas governamentais.

Nessa perspectiva, o que é um aspecto positivo da contemporaneidade, as artes estão cada vez mais conectadas com a realidade, inseridas no cotidiano das pessoas. Como lembra Paulo Felipe Monteiro (1993), no texto Públicos das artes ou artes públicas?, também o termo "arte" teve diferentes significações no decorrer dos tempos, mudou o que é considerado arte, suas relações com outras produções, as fronteiras entre diferentes formas de arte. Para o autor, a modernidade foi uma "estrutura de problemicidade", de tensões, dentre elas o fato de, ao mesmo tempo, ter promovido a instituição do espaço público e a autonomização de diferentes esferas de ação, como a economia, a religião e a arte. Algumas dessas esferas, como é o caso das artes, alcançaram tal autonomia que passaram a operar em circuito fechado, auto-reflexivo e reproduzido. No entanto, apesar de tornarem-se cada vez mais uma esfera autônoma, ao mesmo tempo passaram e continuam passando por todo o desenvolvimento e evolução crescente dos meios de reprodução e comunicação, tornando-se cada vez mais públicas.

[...] por um lado as artes tornaram-se cada vez mais uma esfera autónoma, com os seus próprios critérios, legalidades e ritmos; mas ao mesmo tempo as artes, pelo menos desde a invenção da imprensa a vapor, em 1800, passando 
por todo o desenvolvimento dos meios de reprodução e de comunicação (culminando no vídeo), passaram a ser cada vez mais públicas, passou a haver uma relação cada vez mais pública com as artes ou, pelo menos, com algumas das suas produções. É no seio desta tensão - arte tornada autônoma e arte tornada pública - que se encontra o artista, o produtor e o teórico que reflete sobre a arte. (MONTEIRO, 1993, p. 2-3)

Nesta discussão duas posições podem ser assumidas: a primeira é a que defende a autonomia da arte a partir do estético, a arte em si mesma, distante da sociedade; a segunda é a que considera aspectos positivos nas evoluções e mudanças no significado e na dinâmica das artes. Sobre a primeira posição, Monteiro (1993, p. 4) lembra que tanto Luhmann como Habermas questionaram a forma como Adorno, a Escola de Frankfurt e seus seguidores analisavam a questão. Isso porque tinham como referência as artes tal como definidas na estética setecentista, distinguindo-as do senso comum e do cotidiano. Luhmann defende que há que se ver a autonomia da arte enquanto autonomia na sociedade, Habermas ressalta que para as artes, que são objetos de uma recepção coletiva, desenha-se uma evolução que aponta para além da simples indústria da cultura. A segunda posição é a de Walter Benjamin, que "[...] soube libertar-se do velho queixume de que 'as massas' só procuram o divertimento, enquanto que a verdadeira arte exige o recolhimento". (MONTEIRO, 1993, p. 4-5) Benjamim, ainda nos anos 30, referia-se a passagem do "valor ritual" da arte para um novo valor, que chamou de "exposição". Ou seja, "[...] a arte deixa de ter um enraizamento ritual num sentido previamente conhecido e partilhado mas ganha sentidos sempre que é retomada pela experiência de quem se relaciona com ela, do público". (MONTEIRO, 1993, p. 5) 


\section{Concluindo}

Foi a partir da gestão de Gilberto Gil no MinC que os debates sobre os diferentes significados de cultura e sua importância para as políticas públicas começaram a ganhar novos contornos, mais contemporâneos. Em política, normalmente, as mudanças acontecem somente depois de muito debatidas e experimentadas no cotidiano e no desejo da sociedade. Precisou que um artista consagrado enfrentasse esse desafio e questionasse as políticas culturais vigentes e suas armadilhas. Como registrou Gil em seu discurso de posse em 2003:

[...] ninguém aqui vai me ouvir pronunciar a palavra "folclore". Os vínculos entre o conceito erudito de "folclore" e a discriminação cultural são mais do que estreitos. São íntimos. "Folclore" é tudo aquilo que não se enquadrando, por sua antigüidade, no panorama da cultura de massa é produzido por gente inculta, por "primitivos contemporâneos”, como uma espécie de enclave simbólico, historicamente atrasado, no mundo atual. Os ensinamentos de Lina Bo Bardi me preveniram definitivamente contra essa armadilha.

Se por um lado Gil conseguiu impor e difundir uma compreensão mais ampla do significado de cultura e instituir o paradigma da diversidade e da democracia, por outro lado, as políticas específicas, em especial as políticas para as artes, não tiveram a visibilidade e os avanços esperados - muito embora tenha sido instalado um contexto mais propício para tal, tanto no que se refere à atuação dos setores do governo responsáveis por essas políticas, quanto no que se refere ao incentivo e a criação de instrumentos para uma maior participação da sociedade civil na formulação das políticas culturais em nosso país. 
No que tange a atuação da Funarte, responsável pelas políticas paras as linguagens artísticas, apesar da falta de visibilidade e força política, nos últimos anos a instituição aumentou o seu número de programas de prêmios, editais e bolsas, e teve seu orçamento ampliado. Em 2010, de acordo com a publicação Oito anos de cultura, o orçamento da Funarte foi de R \$ 101,6 milhões, “o valor - sete vezes maior que o de 2003 - é o maior em 21 anos de história" (2010, p. 92).

No entanto, a estrutura e o orçamento da Funarte continuam insuficientes para fomentar a produção artística em toda a sua diversidade e em todas as regiões do país. Em termos de pessoal, vários servidores que ingressaram em 2006 através de concurso público já saíram devido aos melhores salários oferecidos no mercado. Com isso, como acontece em muitas instituições públicas, perde-se também os investimentos feitos em treinamento e qualificação.

Se na gestão Gilberto Gil - Juca Ferreira as políticas para as artes não avançaram tanto quanto o necessário e o desejado, resta esperar que na gestão de Ana de Hollanda à frente do MinC tenhamos continuidade no diálogo com a sociedade para a elaboração e definição das prioridades para cada linguagem, fundamental para que os avanços almejados venham a se concretizar.

Além do investimento nas políticas específicas, é necessário ainda promover a reflexão sobre os diferentes significados das artes hoje, como dialogam e no que coincidem, se aproximam ou se distanciam em relação à compreensão atual de cultura e ao paradigma da diversidade, que se instala e ganha força na disputa por significação cultural na contemporaneidade. 


\section{Notas}

1 "Lo estético, como valor en si mismo, pasa a segundo plano, al tiempo que se le pide a la cultura y al arte que llene los vacios dejados por la política. Desde una perspectiva el arte se instrumentaliza: pareciera que solo fuera significativo cuando sirve para consolidar comunidad, restaurar el tejido social, transformar las historias de exclusión en historias de reconocimiento cultural”.

\section{Referências}

ALMEIDA, Cândido José Mendes, DA-RIN, Silvio (Org.). Marketing cultural ao vivo: depoimentos. Rio de Janeiro: Francisco Alves, 1992.

BARBALHO, Alexandre; RUBIM, Antonio Albino Canelas (Org.). Políticas culturais no Brasil. Salvador: EDUFBA, 2007.

BOTELHO, Isaura. As dimensões da cultura e o lugar das políticas públicas. Revista São Paulo em Perspectiva. São Paulo, v. 15, n. 2, 2001. Disponível em: http://www.centrodametropole.org.br/pdf/Isaura.pdf.

. A política cultural \& o plano das idéias. In: BARBALHO, Alexandre; RUBIM, Albino (Org.). Políticas culturais no Brasil. Salvador: EDUFBA, 2007.

. Romance de formação: Funarte e a política cultural. Rio de Janeiro:

Edições Casa de Rui Barbosa, 2000.

BRASIL. Ministério da Cultura. Oito anos de cultura: as políticas do Ministério da Cultura de 2003 a 2010. Brasília, 2010.

CUNHA, Eneida Leal. A emergência da cultura e da crítica cultural. Cadernos de Estudos Culturais, v. 1, p. 73-82, 2009.

EAGLETON, Terry. A ideia de cultura. Lisboa: Actividades Editoriais, 2005.

FERREIRA, Juca. Discurso do Ministro da Cultura por ocasião da solenidade de transmissão de cargo. Brasília, 28 de agosto de 2008. Disponível em:

http://www.cultura.gov.br/site/2008/08/29/discurso-do-ministro-da-culturajuca-ferreira-na-solenidade-de-transmissao-de-cargo/. Acesso em: 01 fev. 2012.

GAUTIER, Ana Maria Ochoa. Entre los Deseos y los Derechos, Un Ensayo Crítico sobre Políticas Culturales. Bogotá: Instituto Colombiano de Antropología, 2002.

GIL, Gilberto. Discurso de posse do Ministro. Brasília, 2 de janeiro de 2003.

Disponível em: http://www1.folha.uol.com.br/folha/brasil/ult96u44344. shtml. Acesso em: 11 dez. 2011. 
GIL, Gilberto. O papel fundamental da Funarte no Ministério da Cultura. 2004. Disponível em: http://www.funarte.gov.br/wp-content/uploads/2010/11/ ministro.pdf. Acesso em: 01 fev. 2012.

MICELI, Sérgio. Imagens negociadas: retratos da elite brasileira (1920-40). São Paulo: Companhia das Letras, 1996.

MONTEIRO, Paulo Filipe. Público das artes ou artes públicas. 1993. Disponível em: http://www.bocc.ubi.pt/pag/monteiro-paulo-filipe-publicos-artes-pblicas. pdf. Acesso em: 01 fev. 2012.

NUSSBAUMER, Gisele. O mercado da cultura em tempos (pós)modernos. Santa Maria: UFSM, 2000.

PRODUÇÃO, Cultural no Brasil. Rio de Janeiro: Beco do Azougue, 2010. v. 1

RUBIM, Antonio Albino Canelas. Políticas culturais no Brasil: tristes tradições, enormes desafios. In: BARBALHO, Alexandre; RUBIM, Antonio Albino Canelas. (Org.). Políticas culturais no Brasil. Salvador: EDUFBA, 2007.

. Políticas culturais entre o possível e o impossível. In: ENCONTRO DE ESTUDOS MULTIDISCIPLINARES EM CULTURA, 2., 2006. Salvador. Anais... Salvador: Facom/UFBA, 2006. CD-ROM.

SOUZA, Marcio. Fascínio e repulsa: Estado, cultura e sociedade no Brasil. Rio de Janeiro: Edições Fundo Nacional de Cultura, 2000. (Cadernos de Nosso Tempo; 02).

WILLIAMS, Raymond. Cultura. Rio de Janeiro: Paz e Terra, 1992. 
